\title{
A promoter region of the midkine gene that is frequently expressed in human hepatocellular carcinoma can activate a suicide gene as effectively as the $\alpha$-fetoprotein promoter
}

\begin{abstract}
M Tomizawa ${ }^{1,2,8}$, L Yu ${ }^{1,8}$, A Wada $^{1,3}, \mathrm{~T} \mathrm{Tamaoki}^{4}, \mathrm{~K} \mathrm{Kadomatsu}^{5}, \mathrm{~T}_{\text {Muramatsu }}{ }^{5}, \mathrm{~S} \mathrm{Matsubara}^{6}, \mathrm{~K} \mathrm{Watanabe}^{7}$, M Ebara ${ }^{2}$, H Saisho' ${ }^{2}$ S Sakiyama' and M Tagawa ${ }^{*}$,

'Division of Pathology, Chiba Cancer Center, 666-2, Nitona, Chuo-ku, Chiba 260-87 I7, Japan; ²Department of Medicine and Oncology, Graduate School of Medicine, Chiba University, I-8-I Inohana, Chuo-ku, Chiba 260-8670, Japan; ${ }^{3}$ Department of Respirology, Graduate School of Medicine, Chiba University, I-8-I Inohana, Chuo-ku, Chiba 260-8670, Japan; ${ }^{4}$ Department of Medical Biochemistry, University of Calgary, 3330 Hospital Drive NW, Calgary, Alberta, Canada T2N4 NI; ${ }^{5}$ Department of Biochemistry, Nagoya University, School of Medicine, 65 Tsurumai-cho, Showa-ku, Nagoya 4668550, Japan; ${ }^{6}$ Department of Biochemistry, Faculty of Medicine, Kagoshima University, 8-35-I Sakuragaoka, Kagoshima 890-8520, Japan; 'Division of Gastroenterological Surgery, Chiba Cancer Center, 666-2, Nitona, Chuo-ku, Chiba 260-8717, Japan
\end{abstract}

We examined the expression of the midkine (MK) and $\alpha$-fetoprotein (AFP) genes in 15 paired human specimens obtained from hepatocellular carcinoma (HCC) and the corresponding noncancerous regions of the same patients. A total of I4 HCC but none of the noncancerous specimens were positive for the MK mRNA. In contrast, three HCC specimens and one corresponding noncancerous sample out of the three AFP-positive HCC cases expressed the AFP gene. A 2.3-kb genomic fragment in the regulatory region of the MK gene could activate a fused reporter gene in both AFP-producing and -nonproducing HCC lines, and the MK fragment-mediated transcriptional activity was comparable to the AFP enhancer-linked AFP promoter in AFP-producing cell lines. The AFP-producing but not AFP-nonproducing HCC cell lines that were transfected with the MK promoter-linked herpes simplex virus-thymidine kinase (HSV-TK) gene became susceptible to a prodrug ganciclovir to a similar degree of the HCC transfected with the enhancer-linked AFP promoter-fused HSV-TK gene. These data suggest that the MK promoter can activate a therapeutic gene preferentially in HCC and is as useful as the AFP promoter in clinical settings.

British Journal of Cancer (2003) 89, I086- 1090. doi:I0.1038/sj.bjc.660 I 246 www.bjcancer.com

(c) 2003 Cancer Research UK

Keywords: midkine; promoter; hepatocellular carcinoma; $\alpha$-fetoprotein; HSV-TK

Preferential expression of a cytotoxic gene in tumours is a therapeutic approach to cancer treatment. Regulatory sequences of the gene that is expressed primarily in tumours can activate a fused exogenous gene in the tumours and the use of such promoter regions has been investigated for its clinical feasibility (Miller and Whelan, 1997). Regulated expression of a suicide gene with the promoters can primarily destroy tumour cells and leave the surrounding tissues undamaged. The $\alpha$-fetoprotein promoter (AFP) is a representative one to activate an exogenous gene specifically in hepatocellular carcinoma (HCC) (Tamaoki, 2000) and has been applied to targeted gene therapy for HCC (Kanai et al, 1996; Mawatari et al, 1998; Hallenbeck et al, 1999). Precise analysis of the regulatory region of the AFP gene demonstrated that enhancer and silencer elements in the region played a crucial role in the transcription (Nakabayashi et al, 1991) and the silencerdeleted, enhancer-linked AFP promoter showed noticeable therapeutic effects compared with the unmodified AFP promoter (Mawatari et al, 1998).

*Correspondence: Dr M Tagawa;

E-mail: mtagawa@chiba-ccri.chuo.chiba.jp

${ }^{8}$ These authors contributed equally to this work.

Received 24 December 2002; revised 5 June 2003; accepted 8 July 2003
Midkine (MK) is a heparin-binding growth factor (Kadomatsu et al, 1988) with a number of functions: forced expression of MK induced transformation (Kadomatsu et al, 1997) and elevated angiogenesis (Choudhuri et al, 1997). Expression of the $M K$ gene in human adult tissues is extremely low and restricted; however, the expression is upregulated in a number of human tumours particularly in gastrointestinal tumours including HCC (Aridome et al, 1995; Koide et al, 1999). The $5^{\prime}$ upstream region of the $M K$ gene was demonstrated to activate a suicide gene in MK-positive human tumours (Adachi et al, 2000; Miyauchi et al, 2001; Wesseling et al, 2001). In this study, we compared the usefulness of the AFP and the MK promoters for HCC treatment by examining the frequency of $M K$ and $A F P$ expression in human HCC specimens and the transcriptional activity of the promoters in HCC cell lines.

\section{MATERIALS AND METHODS}

\section{Tissue samples and cells}

Paired cancerous and noncancerous specimens obtained from the same HCC patients were provided by the Chiba Cancer Center Tissue Bank. The clinical data regarding respective patients were 
provided by the Bank based on the ethical guideline on human genome study and genetic analysis (issued by the Japanese government in 2001). Histological types of HCC were determined according to the classification of the Liver Cancer Study Group of Japan. Human HCC cells (HuH-7, PLC/PRF/5, HLE and HLF cells), human breast cancer MCF-7 cells and human pancreatic cancer AsPC-1 cells were cultured in Dulbecco's modified Eagle's or RPMI1640 medium supplemented with $10 \%$ fetal calf serum.

\section{Northern blot analysis}

Total RNA $(10 \mu \mathrm{g})$ was isolated with Trizol (Life Technologies, Rockville, MD, USA), subjected to electrophoresis in a denaturing formaldehyde-agarose gel and transferred to a nylon filter. MK (Kadomatsu et al, 1988) and AFP cDNA (Morinaga et al, 1983) were labelled with $\left[{ }^{32} \mathrm{P}\right] \mathrm{dCTP}$ and used as probes. The hybridisation was performed in a solution of $50 \%$ formamide $/ 5 \times \mathrm{SSC} /$ $50 \mathrm{mM} \mathrm{NaH}_{2} \mathrm{PO}_{4} / 2 \times$ Denhardt's solution $/ 0.1 \% \mathrm{SDS} / 0.1 \mathrm{mg} \mathrm{ml}^{-1}$ salmon sperm DNA at $42^{\circ} \mathrm{C}$ for $12 \mathrm{~h}$. The filter was washed with a solution of $0.2 \times \mathrm{SSPE} / 0.1 \%$ SDS several times at $50^{\circ} \mathrm{C}$. The same filter was rehybridised with a human $18 \mathrm{~S}$ ribosome cDNA as a control.

\section{Dual luciferase assay}

The 2335-bp genomic DNA fragment of the $M K$ gene $(-2285 /+50$, +1 corresponds to the transcription start site) (Uehara et al, 1992) was cloned into the pGL2-basic vector (Promega, Madison, WI, USA) that contained the firefly luciferase gene without any promoter sequences (MK2.3-luc). MK2.3kb-luc DNA was digested with $\mathrm{XhoI} /$ Eco47III to produce the 609-bp fragment-linked firefly luciferase genes (MK0.6-luc). The AFP promoter region (AFP0.2, 212-bp SacI/HindIII fragment) and the enhancer (934-bp SwaI/ EcoRI fragment)-linked AFP promoter region (AFPEn0.2) were prepared from pAF5.1-CAT (Nakabayashi et al, 1991), and they were subcloned into pGL2-basic vector (AFP0.2-luc, AFPEn0.2luc). The transcriptional activity was measured with the dual luciferase reporter assay system (Promega). Plasmid DNA containing respective genomic fragments, pGL2-control vector (Promega) harbouring the SV40 promoter-linked firefly luciferase gene (SV40-luc) or pGL2-basic, together with a control vector, the renilla luciferase gene fused with the HSV-TK promoter (pRL-TK,
Promega) at a molar ratio of $10: 1$, was transfected into target cells with a lipofectin reagent (Life Technologies, Gaithersburg, MD, USA). After 2 days, cells were lysed and the luciferase activities were measured according to the manufacturer's protocol. The relative firefly luciferase activity of each cell lysate was calculated based on the amount of luminescence produced by renilla luciferase and was expressed as a percentage of the SV40 promoter-mediated activity. All of the values were expressed as a mean of four independent experiments. The statistical analysis was performed by one-way analysis of variance (ANOVA).

\section{In vitro sensitivity to ganciclovir}

The $2.3 \mathrm{~kb}$. MK or the enhancer-linked AFP promoter region was ligated into pcDNA3 vector (Invitrogen, San Diego, CA, USA) from which the cytomegalovirus promoter was removed. The herpes simplex virus-thymidine kinase (HSV-TK) gene was then cloned into the downstream of the promoters (MK2.3-TK, AFPEn0.2-TK). Cells were transfected with MK2.3-TK, AFPEn0.2-TK or pcDNA3 vector DNA and G418 (Life Technologies)-resistant cells were selected. The pooled cells were seeded in 96-well plates at a density of $5 \times 10^{3}$ cells well $^{-1}$ and were cultured with various concentrations of ganciclovir (GCV). After 5 days, viable cells in each well were measured with a cell-counting kit (Wako, Osaka, Japan). The amount of formazan produced in each well was determined from the absorbance at $450 \mathrm{~nm}$.

\section{RESULTS}

\section{Expression of the $M K$ and $A F P$ genes in HCC}

We examined the frequency of expressed $M K$ and AFP genes in paired HCC and noncancerous specimens of the same patients by Northern blot analysis. In all, 14 out of 15 HCC specimens but none of the corresponding noncancerous samples was positive for $M K$ mRNA expression. Three HCC specimens expressed the AFP gene and one of the AFP-positive samples was also AFP-positive in the corresponding noncancerous region (Table 1, Figure 1). Frequency and tumour specificity of the expression in human HCC was thus greater for the $M K$ compared with the AFP gene. Serum AFP values of the patients were not correlated with the results of AFP mRNA expression.

Table I Expression of the MK and AFP genes in human HCC specimens

\begin{tabular}{|c|c|c|c|c|c|c|c|c|c|}
\hline \multirow[b]{2}{*}{ No } & \multirow[b]{2}{*}{ Age } & \multirow[b]{2}{*}{ Gender } & \multirow[b]{2}{*}{ HBs antigen } & \multirow[b]{2}{*}{ HCV antibody } & \multicolumn{2}{|c|}{ Pathology } & \multicolumn{2}{|l|}{ Expression $^{\mathbf{a}}$} & \multirow[b]{2}{*}{$\begin{array}{l}\text { Serum AFP } \\
\left(\mathbf{n g ~ ~ m l ^ { - 1 } )}\right.\end{array}$} \\
\hline & & & & & HCC & Noncancerous & $\begin{array}{c}\text { MK } \\
\text { (HCC/Noncancerous) }\end{array}$ & AFP & \\
\hline । & 23 & $M$ & + & - & mode, trab/pseud & $\mathrm{CH}$ & $+1-$ & $+/+$ & 21 \\
\hline 2 & 48 & $M$ & + & - & mode, sci & $\mathrm{CH}$ & $+1-$ & $+1-$ & 10892 \\
\hline 3 & 52 & $M$ & + & - & mode, trab & $\mathrm{CH}$ & $+1-$ & $-1-$ & 70 \\
\hline 4 & 57 & $M$ & - & + & mode, trab & $\mathrm{CH}$ & $+1-$ & $-1-$ & 23 \\
\hline 5 & 61 & $M$ & - & + & well, trab & $\mathrm{CH}$ & $+1-$ & $-1-$ & 15 \\
\hline 6 & 66 & $M$ & - & + & poor, com & $\mathrm{CH}$ & $+1-$ & $-1-$ & 5 \\
\hline 7 & 68 & $M$ & - & + & mode, trab & $\mathrm{CH}$ & $+1-$ & $-1-$ & 3 \\
\hline 8 & 69 & $M$ & + & - & mode, trab & $\mathrm{CH}$ & $+1-$ & $-1-$ & 26 \\
\hline 9 & 73 & $M$ & + & - & mode, trab & $\mathrm{CH}$ & $+1-$ & $-1-$ & 124 \\
\hline 10 & 49 & $F$ & + & - & mode, trab & $\mathrm{CH}$ & $+1-$ & $-1-$ & 3 \\
\hline |1 & 52 & $\mathrm{~F}$ & NA & NA & poor, com & $\mathrm{CH}$ & $-1-$ & $-1-$ & 41 \\
\hline 12 & 58 & $F$ & + & - & mode, trab & $\mathrm{CH}$ & $+1-$ & $+1-$ & 1434 \\
\hline 13 & 59 & $\mathrm{~F}$ & - & + & well, trab & $\mathrm{CH}$ & $+1-$ & $-1-$ & 572 \\
\hline 14 & 74 & $\mathrm{~F}$ & - & + & mode, trab & LC & $+1-$ & $-1-$ & 2999 \\
\hline 15 & 55 & $M$ & - & + & well, trab & $\mathrm{LC}$ & $+1-$ & $-1-$ & 14 \\
\hline
\end{tabular}

Abbreviations: $M=$ male, $F=$ female, $N A=$ not available, well = well differentiated, mode= moderately differentiated, poor = poorly differentiated, trab = trabecular type, pseu = pseudoglandular type, com = compact type, sci=scirrhous type, $\mathrm{CH}=$ chronic hepatitis, $\mathrm{LC}=$ liver cirrhosis. ${ }^{\mathrm{a}}$ Expression of the $\mathrm{MK}$ and $\mathrm{AFP}$ genes in HCC and noncancerous region of the same patients was examined with Northern blot analysis and was shown as positive (+) or negative (-). ${ }^{b}$ Serum AFP before surgical operation. 


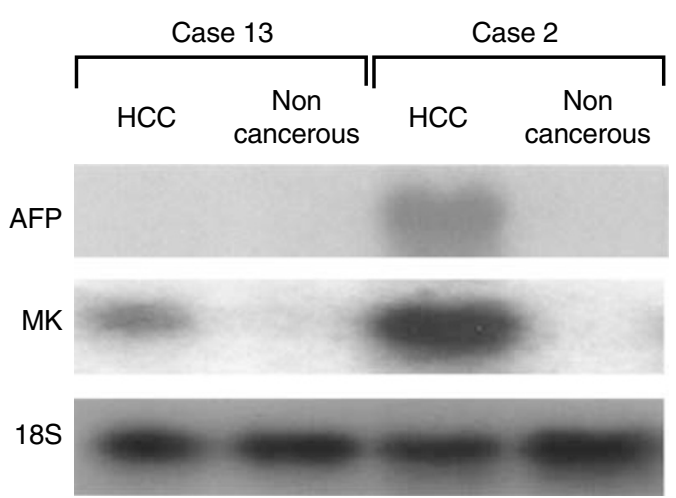

Figure I Expression of the MK and AFP genes in human surgical specimens was examined with Northern blot analysis. Representative samples were shown and the expression of I 85 ribosomal RNA gene was used as controls.

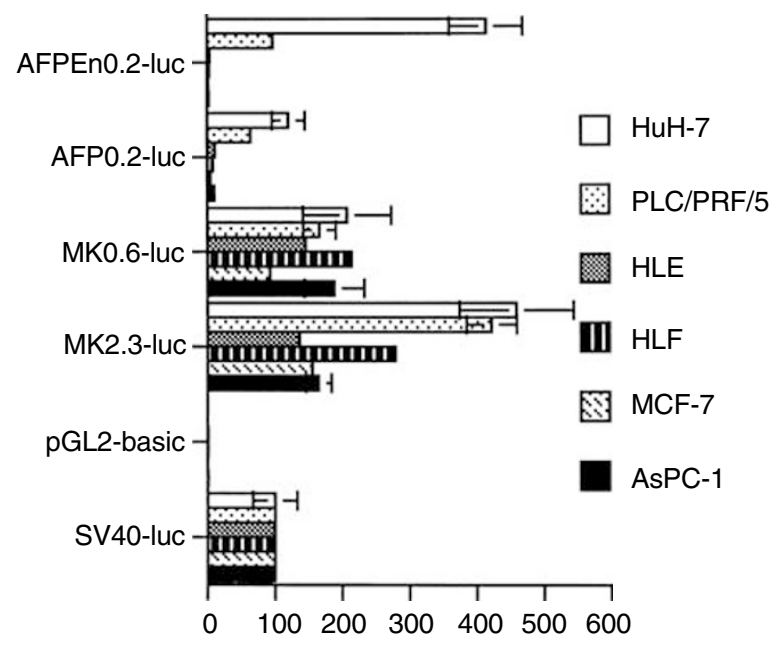

Relative luciferase assay (\%)

Figure 2 Transcriptional activity of the MK and AFP genomic fragments tested in AFP-producing HCC (HuH-7 and PLC/PRF/5), AFP-nonproducing HCC (HLE and HLF) and non-HCC (MCF-7 and AsPC-I) cells. The relative firefly luciferase activity was expressed as a percentage of the SV4O promoter-mediated activity. Standard error bars are also shown.

\section{Transcriptional activity of MK and AFP promoter}

We investigated the transcriptional activity of MK and AFP promoters with the luciferase reporter assay. Our previous studies showed that a 2.3- or a 0.6-kb genomic fragment of the $M K$ gene contained cis-acting elements, which could activate an exogenous gene preferentially in tumours (Miyauchi et al, 2001; Yoshida et al, 2002). Linkage of 0.2-kb AFP promoter and 0.9-kb AFP distal enhancer gave the maximal transcription of a fused reporter gene (Nakabayashi et al, 1991). We thereby examined the transcriptional activity of four kinds of reporter constructs (MK2.3-luc, MK0.6-luc, AFP0.2-luc and AFPEn0.2-luc) in AFP-producing (HuH-7 and PLC/PRF/5) and -nonproducing (HLE and HLF) HCC cell lines (Niwa et al, 1996; Ishikawa et al, 1999), and in nonHCC cell lines (MCF-7 and AsPC-1), which were positive for MK expression (Miyauchi et al, 2001).

Introduction of the respective reporter genes into HCC cell lines revealed that transcriptional activity of the $2.3-$ or $0.6-\mathrm{kb} \mathrm{MK}$ fragment was greater than that of the SV40 or the AFP promoter $(P<0.001$, Figure 2). Since HuH-7 and PLC/PRF/5 cells are AFPhigh and AFP-intermediate producers, respectively (Niwa et al, 1996; Ishikawa et al, 1999), the transcriptional activity of the AFP promoter was greater in $\mathrm{HuH}-7$ than in PLC/PRF/5 cells. Addition of AFP enhancer augmented the AFP promoter-mediated transcriptional activation particularly in $\mathrm{HuH}-7$ cells $(P<0.001)$. The luciferase activity of AFPEn0.2-luc DNA was then comparable to that of the MK2.3-luc DNA in HuH-7 cells. In AFP-nonproducers, however, the transcriptional activity of the AFP promoter or the enhancer-linked AFP promoter was minimal.

The transcriptional activity of the $2.3-$ or $0.6-\mathrm{kb} \mathrm{MK}$ fragment was comparable to that of the SV40 promoter in non-HCC cells as previously reported (Miyauchi et al, 2001) and the AFP promoter did not activate the fused luciferase gene in these cells.

\section{In vitro sensitivity to $\mathrm{GCV}$}

We compared increased cytotoxic activity caused by the HSV-TK/ GCV system using the MK and the AFP promoters. All the cells were transfected with MK2.3-TK, AFPEn0.2-TK or vector DNA and then respective G418-resistant cells were exposed to various concentrations of GCV (Figure 3). The sensitivity of vector DNAtransfected cells was not different from that of respective parent cells. However, AFP-producing $\mathrm{HuH}-7$ and $\mathrm{PLC} / \mathrm{PRF} / 5$ cells increased the susceptibility to GCV, when they were transfected
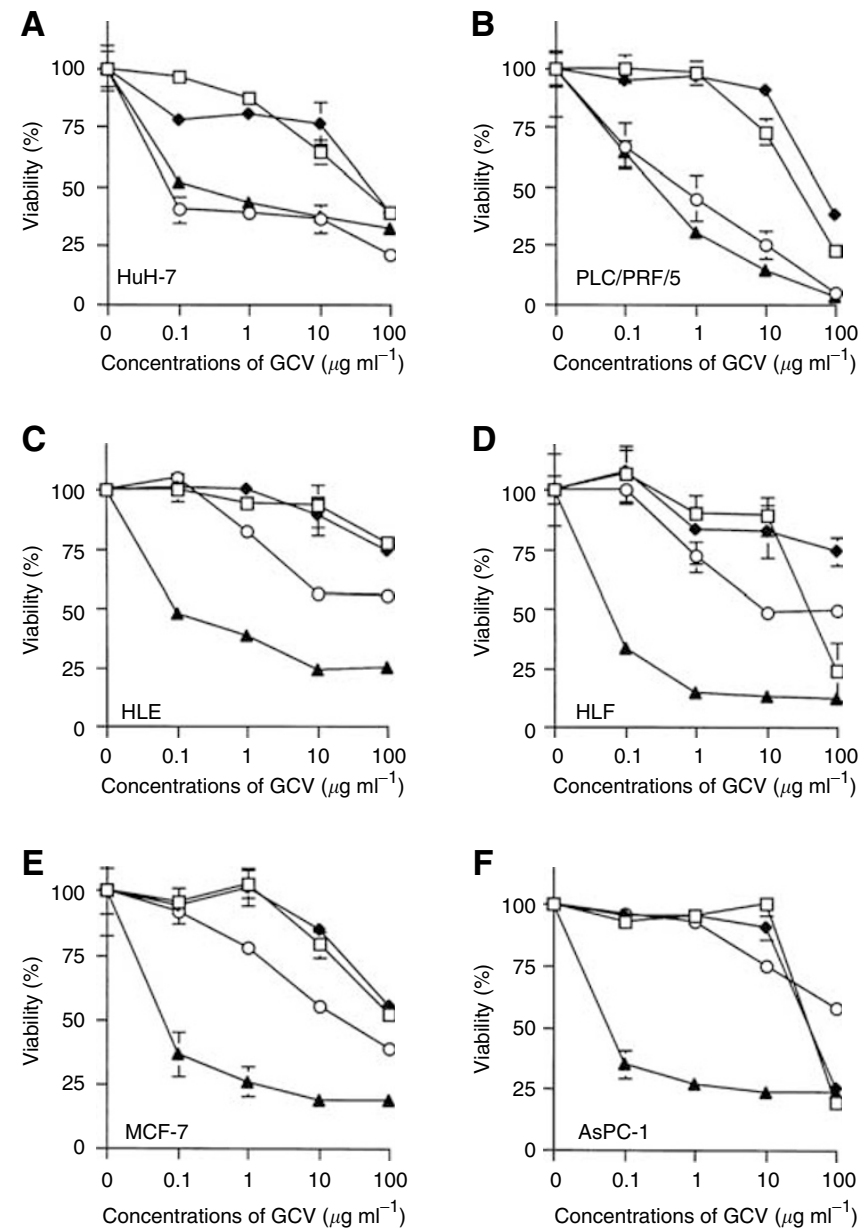

$$
\longrightarrow \text { - Parent } \multimap-\text { AFPEn0.2-TK } \longrightarrow \text { Vector } \longrightarrow \text { MK2.3-TK }
$$

Figure 3 Susceptibility of $\mathrm{HuH}-7$ (A), PLC/PRF/5 (B), HLE (C), HLF (D), MCF-7 (E) and AsPC-I (F) cells to various concentrations of GCV. Parent cells and G4I8-resistant cells that were transfected with vector, MK2.3-TK or AFPEn0.2-TK DNA were used. Standard error bars are also shown. 
with MK2.3- or AFPEn0.2-TK DNA (Figure 3A and B). PLC/PRF/5 cells were more susceptible to GCV than HuH-7 cells, although the transcriptional activity of both $\mathrm{MK}$ and AFP promoters was stronger in $\mathrm{HuH}-7$ than in $\mathrm{PLC} / \mathrm{PRF} / 5$ cells. AFP-nonproducing HCC and non-HCC cells that were transfected with MK2.3-TK DNA significantly increased their susceptibility to GCV and those transfected with AFPEn 0.2-TK DNA also slightly increased the susceptibility (Figure $3 \mathrm{C}-\mathrm{F}$ ). The increased sensitivity of the AFPEn0.2-TK transfectants, despite minimal transcriptional activity of the AFPEn 0.2 DNA in these cells, was probably due to multiple integration of transfected DNA, in which condition cellular and/or plasmid-derived promoters could activate the TK gene.

\section{DISCUSSION}

In this study, we showed that human HCC specimens expressed the $M K$ gene more frequently than the AFP gene and that the transcriptional activity of the MK promoter was as strong as that of the enhancer-linked AFP promoter. The present data also indicate that the MK promoter could activate the HSV-TK gene in HCC cells to a similar extent as the AFP promoter. The AFP promoter has been used to activate a suicide gene in HCC cell lines (Kanai et al, 1996; Mawatari et al, 1998), to produce a hybrid promoter in combination with other regulatory regions (Ido et al, 2001) and to apply to oncolytic adenovirus (Hallenbeck et al, 1999). These previous studies suggested the feasibility of the AFP promotermediated gene therapy for HCC. However, relatively low frequency of AFP expression in human HCC may hamper the clinical application. Although serum AFP was elevated in $70 \%$ of HCC patients (Nakabayashi et al, 1991), AFP transcripts were not frequently detected with Northern blot analysis as shown in the present study. Di Biscegile et al. (1986) reported that nine out of 10 HCC patients showed elevated serum AFP values, but only two out of the 10 HCC specimens were positive for the mRNA with Northern blot analysis. Similar cases, high serum AFP values with undetectable AFP transcript with Northern blot analysis, were also reported (Varagona et al, 1992; Niwa et al, 1996), although the level of AFP mRNA expression in general correlated with serum AFP levels (Niwa et al, 1996). With more sensitive methods, noncancerous samples as well as HCC specimens turned out to be positive for AFP mRNA expression, since preneoplastic cells in liver cirrhosis could produce AFP (Otsuru et al, 1988). These data

\section{REFERENCES}

Adachi Y, Reynolds PN, Yamamoto M, Grizzle WE, Overturf K, Matsubara S, Muramatsu T, Curiel DT (2000) Midkine promoter-based adenoviral vector gene delivery for pediatric solid tumors. Cancer Res 60: 4305-4310

Aridome K, Tsutsui J, Takao S, Kadomatsu K, Ozawa M, Aikou T, Muramatsu T (1995) Increased midkine gene expression in human gastrointestinal cancers. Jpn J Cancer Res 86: 655-661

Choudhuri R, Zhang HT, Donnini S, Ziche M, Bicknell R (1997) An angiogenic role for the neurokines midkine and pleiotrophin in tumorigenesis. Cancer Res 57: 1814- 1819

Di Bisceglie AM, Dusheiko GM, Paterson AC, Alexander J, Shouval D, Lee CS, Beasley RP, Kew MC (1986) Detection of alpha-foetoprotein messenger RNA in human hepatocellular carcinoma and hepatoblastoma tissue. Br J Cancer 54: 779-785

Hallenbeck PL, Chang YN, Hay C, Golightly D, Stewart D, Lin J, Phipps S, Chiang YL (1999) A novel tumor-specific replication-restricted adenoviral vector for gene therapy of hepatocellular carcinoma. Hum Gene Ther 10: $1721-1733$

Heise C, Kirn DH (2000) Replication-selective adenoviruses as oncolytic agents. J Clin Invest 105: $847-851$

Ido A, Uto H, Moriuchi A, Nagata K, Onaga Y, Onaga M, Hori T, Hirono S, Hayashi K, Tamaoki T, Tsubouchi $\mathrm{H}$ (2001) Gene therapy targeting for collectively raise the possibility that the AFP promoter may not activate fused exogenous genes in some of serum AFP-positive HCC cases. On the contrary, frequent expression of the $M K$ gene implies a possible strategy of MK promoter-based therapy for HCC patients, although the expression is not specific to HCC.

The specificity of transcriptional activity by the MK and the AFP promoter has been already demonstrated; both promoters could drive the fused gene in respective MK- or AFP-positive cells but not in MK- or AFP-negative cells (Kanai et al, 1996; Miyauchi et al, 2001). The mechanism of preferential expression of the $M K$ gene in tumours was not fully understood. It could be related with cell growth: forced expression of MK in fibroblasts induced cell transformation (Kadomatsu et al, 1997) and suppressed expression of MK inhibited the tumour growth (Takei et al, 2001).

Recent studies demonstrated feasible application of tumourspecific promoters to oncolytic adenovirus, which could replicate within tumours but not in normal tissues (Heise and Kirn, 2000). The MK promoter-mediated oncolytic adenovirus was not harmful to liver but killed MK-positive tumours (Adachi et al, 2000). These data suggested that MK promoter-based gene therapy could facilitate selective killing of HCC and keep surrounding noncancerous tissues undamaged. The present Northern blot analysis, in fact, implied that MK promoter-mediated gene therapy for HCC would not injure surrounding cirrhosis tissues. Extracorporal intratumoural injection technique could also broaden the application of MK promoter-based therapy for HCC patients. Since maintenance of residual liver functions is crucial for HCC treatment, the MK promoter could provide an alternative therapeutic approach besides AFP promoter-based therapy. The present study suggested that the AFP promoter and the MK promoter are applicable to AFP-high- and AFP-low/ nonproducing HCC, respectively, and the feasibility of both kinds of the promoter-based therapy will be investigated in clinical settings.

\section{ACKNOWLEDGEMENTS}

This work was supported by grants-in-aid for scientific research from the Japan Society for the Promotion of Science (JSPS) and from the Uehara Memorial Foundation. L Yu is supported by the JSPS postdoctoral fellowship. We thank F Hoffman-La Roche (Basel, Switzerland) for their generous gift of GCV.

hepatocellular carcinoma: selective and enhanced suicide gene expression regulated by a hypoxia-inducible enhancer linked to a human $\alpha$ fetoprotein promoter. Cancer Res 61: 3016-3021

Ishikawa H, Nakata K, Mawatari F, Ueki T, Tsuruta S, Ido A, Nakao K, Kato Y, Ishii N, Eguchi K (1999) Utilization of variant-type of human $\alpha$ fetoprotein promoter in gene therapy targeting for hepatocellular carcinoma. Gene Ther 6: 465-470

Kadomatsu K, Tomomura M, Muramatsu T (1988) cDNA cloning and sequencing of a new gene intensely expressed in early differentiation stages of embryonal carcinoma cells and in mid-gestation period of mouse embryogenesis. Biochem Biophys Res Commun 151: 1312-1318

Kadomatsu K, Hagihara M, Akhter S, Fan QW, Muramatsu H, Muramatsu $\mathrm{T}$ (1997) Midkine induces the transformation of NIH3T3 cells. $\mathrm{Br} J$ Cancer 75: $354-359$

Kanai F, Shiratori Y, Yoshida Y, Wakimoto H, Hamada H, Kanegae Y, Saito I, Nakabayashi H, Tamaoki T, Tanaka T, Lan KH, Kato N, Shiina S, Omata M (1996) Gene therapy for alpha-fetoprotein-producing human hepatoma cells by adenovirus-mediated transfer of the herpes simplex virus thymidine kinase gene. Hepatology 23: 1359-1368

Koide N, Hada H, Shinji T, Ujike K, Hirasaki S, Yumoto Y, Hanafusa T, Kadomatsu K, Muramatsu H, Muramatsu T, Tsuji T (1999) Expression of 
the midkine gene in human hepatocellular carcinomas. Hepatogastroenterology 46: $3189-3196$

Mawatari F, Tsuruta S, Ido A, Ueki T, Nakao K, Kato Y, Tamaoki T, Ishii N, Nakata K (1998) Retrovirus-mediated gene therapy for hepatocellular carcinoma: Selective and enhanced suicide gene expression regulated by human $\alpha$-fetoprotein enhancer directly linked to its promoter. Cancer Gene Ther 5: 301-306

Miller N, Whelan J (1997) Progress in transcriptionally targeted and regulatable vectors for genetic therapy. Hum Gene Ther 8: 803-815

Miyauchi M, Yoshida Y, Tada Y, Narita M, Maeda T, Bahar R, Kadomatsu K, Muramatsu T, Matsubara S, Nakagawara A, Sakiyama S, Tagawa M (2001) Expression of herpes simplex virus-thymidine kinase gene controlled by a promoter region of the midkine gene confers selective cytotoxicity to ganciclovir in human carcinoma cells. Int J Cancer 91: 723-727

Morinaga T, Sakai M, Wegmann TG, Tamaoki T (1983) Primary structures of human alpha-fetoprotein and its mRNA. Proc Natl Acad Sci USA 80: $4604-4608$

Nakabayashi H, Hashimoto T, Miyao Y, Tjong KK, Chan J, Tamaoki T (1991) A position-dependent silencer plays a major role in repressing alpha-fetoprotein expression in human hepatoma. Mol Cell Biol 11: $5885-5893$

Niwa $Y$, Matsumura $M$, Shiratori $Y$, Imamura $M$, Kato $N$, Shiina $S$, Okudaira T, Ikeda Y, Inoue T, Omata M (1996) Quantitation of alphafetoprotein and albumin messenger RNAs in human hepatocellular carcinoma. Hepatology 23: 1384-1392
Otsuru A, Nagataki S, Koji T, Tamaoki T (1988) Analysis of alphafetoprotein gene expression in hepatocellular carcinoma and liver cirrhosis by in situ hybridization. Cancer 62: 1105-1112

Takei Y, Kadomatsu K, Matsuo S, Itoh H, Nakazawa K, Kubota S, Muramatsu T (2001) Antisense oligodeoxynucleotide targeted to Midkine, a heparin-binding growth factor, suppresses tumorigenicity of mouse rectal carcinoma cells. Cancer Res 61: 8486-8491

Tamaoki T (2000) Human alpha-fetoprotein transcriptional regulatory sequences. Application to gene therapy. Adv Exp Med Biol 465: 47-56

Uehara K, Matsubara S, Kadomatsu K, Tsutsui J, Muramatsu T (1992) Genomic structure of human midkine (MK), a retinoic acid-responsive growth/differentiation factor. $J$ Biochem 111: $563-567$

Varagona G, Brown D, Haase A, Dusheiko G (1992) Increased steady-state levels of alpha-fetoprotein mRNA in hepatocellular carcinoma: an analysis by in situ hybridization. Liver 12: $62-68$

Wesseling JG, Yamamoto M, Adachi Y, Bosma PJ, van Wijland M, Blackwell JL, Li H, Reynolds PN, Dmitriev I, Vickers SM, Huibregtse K, Curiel DT (2001) Midkine and cyclooxygenase-2 promoters are promising for adenoviral vector gene delivery of pancreatic carcinoma. Cancer Gene Ther 8: $990-996$

Yoshida Y, Tomizawa M, Bahar R, Miyauchi M, Yamaguchi T, Saisho $\mathrm{H}$, Kadomatsu K, Muramatsu T, Matsubara S, Sakiyama S, Tagawa M (2002) A promoter region of midkine gene can activate transcription of an exogenous suicide gene in human pancreatic cancer. Anticancer Res 22: $117-120$ 